\title{
Circadian Rhythms in Doxorubicin Nuclear Uptake and Clock Control of C6 Glioma Cells
}

\author{
Ashapurna Sarma, Vishal P. Sharma, Michael E. Geusz \\ Department of Biological Sciences, Bowling Green State University, Bowling Green, USA \\ Email:mgeusz@bgsu.edu
}

Received 1 July 2016; accepted 7 August 2016; published 10 August 2016

Copyright $@ 2016$ by authors and Scientific Research Publishing Inc.

This work is licensed under the Creative Commons Attribution International License (CC BY). http://creativecommons.org/licenses/by/4.0/

(c) (i) Open Access

\begin{abstract}
Alterations of drug efficacy by the circadian clock are a concern when assessing drug therapies. Circadian rhythms persist in some cancer cells and are repressed in others. A better understanding of circadian activities generated within cancer cells could indicate therapeutic approaches that selectively disrupt rhythms and deprive cells of any benefits provided by circadian timing. Another option is to induce expression of the core clock gene Per2 to suppress cancer cell proliferation. We used the $\mathbf{C 6}$ rat glioblastoma cell line to identify rhythmic cancer cell properties that could provide improved therapeutic targets. Nuclear uptake of the anti-cancer agent doxorubicin by $\mathrm{C6}$ cells showed a circadian rhythm that was shifted six hours from the rhythm in Per2 expression. We also observed circadian expression of the Crm1 (Xpo1) gene that is responsible for a key component of molecular transport through nuclear pores. C6 cultures include glioma stem cells (GSCs) that have elevated resistance to chemotherapeutic agents. We examined C6 tumorsphere cultures formed from GSCs to determine whether Hes1 and Bmi1 genes that maintain GSCs are under circadian clock control. Unlike Per2 gene expression in tumorspheres, Hes1 and Bmi1 expression did not oscillate in a circadian rhythm. These results highlight the importance of the nuclear pore complex in cancer treatments and suggest that the nuclear export mechanism and genes maintaining the cancer stem cell state could be inhibited therapeutically at a particular phase of the circadian cycle while preserving the tumor-suppressing abilities of Per2 gene expression.
\end{abstract}

\section{Keywords}

Nucleocytoplasmic Transport, Circadian Pacemaker, Glioblastoma, Exportin, Chemotherapy

\section{Introduction}

The numerous circadian rhythms of the body impact tumor growth and offer opportunities for maximizing anticancer treatments through drug delivery at an identified optimal time of day [1]-[5]. This therapeutic approach 
would benefit from greater understanding of circadian cancer cell properties such as period, amplitude, and, most importantly, phase relative to rhythms in the rest of the body. Daily variability in pharmacodynamics is driven in part by circadian rhythms outside the tumor, but circadian rhythms generated within the cancer cell also likely impact drug efficacy. Even though circadian rhythms in various tumors have been described as disrupted, many cancer cell lines that are capable of forming tumors display distinct circadian rhythms in vitro [6]-[9], suggesting that they may rely on this timing. If so, numerous circadian oscillations in cancer cells are potential targets for therapeutic intervention [10], particularly rhythms controlling metabolism, growth, replication, and invasiveness, which are yet to be fully characterized [11].

Cancer cells are, however, highly heterogeneous [12], and even cancers within a single body system, such as gliomas, differ considerably. Like normal cells, some cancer cells also appear to benefit from their own circadian rhythms, as has been shown for leukemia [13]. This view is at odds with evidence that loss of circadian rhythms within the tumor or elsewhere in the body causes greater tumorigenesis and aggressive cancers [14]-[17]. Also unclear is how the core clock proteins that generate the molecular timing of the circadian clock act on various kinds of cancer. The core protein PER2 is considered to be a tumor suppressor, whereas evidence indicates other core proteins promote cancer cell survival and proliferation [18]-[20], apparently independent of their roles in the circadian clock.

Although circadian clocks are found in most cell types of the body, the suprachiasmatic nucleus (SCN) in the hypothalamus synchronizes clocks within and outside the brain. The SCN receives retinal light information that it uses to bring the peripheral clocks into a preferred phase relationship with the environmental cycle. Pharmacological agents are becoming available for use in directly altering the molecular circadian timing mechanism [21] [22], which could provide more precise chronotherapies for cancers that either benefit from or are repressed by circadian timing or core clock proteins.

Even the genetically compromised and dysregulated cancer cells in aggressive gliomas display circadian rhythms when maintained in vitro. For example, circadian oscillations in gene expression observed in neurons and astrocytes are also present in the C6 rat glioma cell line [9] [23]. In contrast, cancer cell lines that are reported to have suppressed or disrupted circadian timing show epigenetically modified regulatory regions of genes, such as Per2, needed in the coupled transcription-translation feedback loops that generate circadian rhythms [22]-[24]. Nevertheless, the heterogeneity of cancer cell lines or tumor cell populations suggests that some cancer cells can remain rhythmic while their detection is obscured by arrhythmic cells that may form the bulk of the tumor. One such cell type is the glioma stem cells (GSCs) of C6 that were described as circadian oscillators within tumorsphere cultures [23]. One challenge is to determine whether GSCs are also rhythmic within gliomas, in which case chronotherapies could target this potentially dangerous cell type more effectively.

Because circadian clocks in cancer cells are poorly understood targets for cancer drug development, in part because of tumor complexity, this study examined key circadian oscillations in a simplified glioma cell model. Circadian control of protein movement through the nuclear envelope was examined, which is critical to the circadian timing mechanism and the many clock-controlled genes that it regulates. Tumor suppression and export of signaling molecules involved in cell division and cancer cell death also depend heavily on this nucleocytoplasmic transport. Most of the nuclear transport receptors and nuclear pore proteins, broadly defined here as nuclear transport components (NTCs), are known to be regulated abnormally in cancer [24]. One of the NTCs, CRM1 (XPO1), is used for cancer prognosis and therapeutics [25]. CRM1 levels are elevated in most cancer cells including gliomas [26]. Furthermore, CRM1 partners with a second export protein, Nup98, which is frequently mutated in various types of leukemia [27]-[30]. A similar mutation in the nuclear pore protein NUP214 is found in B-cell acute lymphoblastic leukemia [31] [32].

Identifying and understanding circadian clock regulation of nuclear transport is also important because many chemotherapeutic drugs are nuclear targeted. One such drug, doxorubicin (DOX), is among the most effective anticancer drugs [33]. DOX, also known as adriamycin, is effective against a wide range of malignant tumors [34] and damages malignant cell DNA through several mechanisms [35] [36]. Cellular uptake of DOX and its nuclear entry is characterized as a 3-step process: First, DOX enters cancer cells by simple diffusion and binds with high affinity to 20S proteosomal subunit of the proteasome in the cytoplasm. Next, this DOX proteasome complex is transported into the nucleus via the nuclear pore complex. Finally, DOX dissociates from the proteasome and binds to DNA, with higher affinity than the proteasome [35]-[37].

Here we describe circadian rhythms in DOX nuclear accumulation in synchronized C6 cells. Crm1 gene expression in C6 cells was also found to oscillate across the day, suggesting new clock-controlled targets for control of 
glioma cells. Finally, the expression patterns of two genes that maintain glioma stem cells were examined in relation to the circadian clock.

\section{Materials and Methods}

\subsection{Cell Culture}

Rat C6 glioma cells obtained from American Type Cell Culture (catalog number CCL-107) were cultured in what was designated as complete medium that consisted of Dulbecco's Modified Eagle Medium (DMEM) containing penicillin $(100 \mathrm{units} / \mathrm{ml})$, streptomycin $(100 \mu \mathrm{g} / \mathrm{ml}), 10 \%$ fetal bovine serum (FBS) and no pyruvate or phenol red. Cells were grown in $100-\mathrm{mm}$ tissue culture dishes and incubated at $37^{\circ} \mathrm{C}$ in $5 \% \mathrm{CO}_{2}$. Cells were passaged when they reached near confluency. C6 cell lines were co-transfected with a mPer2::mPer2:luc construct, which produced a fusion protein containing mPER2 and firefly luciferase along with the product of CMV::neo [23] These cells were used for all experiments.

To produce tumorspheres, cells were grown in either high glucose serum-free DMEM without pyruvate and with $10 \%$ FBS added (serum medium, SM) or in a stem cell medium (SCM) containing $20 \mathrm{ng} / \mathrm{ml}$ epidermal growth factor (EGF); $15 \mathrm{ng} / \mathrm{ml}$ fibroblast growth factor-2 (FGF2, Life Technologies); and $15 \mathrm{ng} / \mathrm{ml}$ plateletderived growth factor-AB (PDGF-AB) (PeproTech) in the same DMEM and without serum. Penicillin and streptomycin were added to all media.

\subsection{Bioluminescence Assay}

Cells were seeded $\left(10^{5} /\right.$ dish) in 35-mm tissue culture dishes and incubated in DMEM containing $10 \%$ FBS at $37^{\circ} \mathrm{C}$ in $5 \% \mathrm{CO}_{2}$. When plates were $90 \%-100 \%$ confluent, they were washed twice with a $10 \mathrm{mM}$ Hepes-buffered, low-bicarbonate, phenol red-free DMEM designed for use in room air [38], along with $10 \%$ FBS, designated as final medium (FM), After an exchange with Hepes-buffered medium, cells were treated with $20 \mu \mathrm{M}$ forskolin (Sigma-Aldrich) for 2 hours to synchronize the cellular circadian clocks. Immediately before bioluminescence imaging, $0.2 \mathrm{mM}$ of the luciferase substrate luciferin (Xenogen) was added. To monitor rhythmic expression of the PER2 clock protein, bioluminescence was recorded using a Wallac Victor 1420 Multilabel plate reader (Perkin Elmer). The plates were maintained at $37^{\circ} \mathrm{C}$ while readings were taken repeatedly for 50 or $96 \mathrm{hrs}$. The background noise was subtracted from each reading and signals were summed across replicate cultures.

\subsection{Confocal Time-Lapse Imaging of Doxorubicin Nuclear Transport}

C6 cells for imaging were seeded $\left(10^{5}\right.$ cells/dish) in 35-mm tissue culture dishes and incubated overnight in DMEM containing $10 \% \mathrm{FBS}$ at $37^{\circ} \mathrm{C}$ in $5 \% \mathrm{CO}_{2}$. The cells were washed twice with FM. After the exchange with Hepes-buffered medium, cells were treated with $20 \mu \mathrm{M}$ forskolin for 2 hrs to synchronize the cellular circadian clocks. After two hours, cells were rinsed again and imaged on the confocal microscope system with a DMI3000B inverted microscope (Leica Microsystems) equipped with a Spectra X LED light engine (Lumencore), X-Light spinning-disk confocal unit (CrestOptics) and a RoleraThunder cooled CCD camera with back-thinned, back-illuminated, electron-multiplying sensor (Photometrics) with Metamorph software controlling image acquisition and data analysis (Molecular Devices). Confocal images were collected with a 63X oil immersion objective using standard fluorescein filter wavelengths. Cells were first imaged for autofluorescence. Cells were then treated with $10 \mu \mathrm{M}$ DOX and immediately imaged to quantify nuclear transport with a timelapse feature of Metamorph. A single field of view was captured at 5-min intervals over a period of 120 min. The time point at $2 \mathrm{hrs}$ after the forskolin treatment was the 0 -hr circadian time point. Using the same method of synchronization, DOX treatment, and time-lapse confocal imaging, data were collected from other circadian time points at hours $6,12,18,24,36$, and 48.

\subsection{Data Analysis}

Confocal fluorescence images at each 5-min interval were collected into a stack for each circadian time point. The background intensity of the images was subtracted based on the average intensity measurements from controls in which cells were not treated with DOX. ImageJ software (NIH) was used to draw a region-of-interest (ROI) in the nucleus of all the cells in the frame from the middle of the image stack. The maximal fluorescence intensity of the ROIs was measured. The average of the maximal fluorescence intensity of DOX in the nucleus 
of all cells in the field of view was used for every time point in the 120-min time lapse video images at all the circadian phases. The averages across the 120-min time series after DOX treatment for each circadian phase were also measured.

\subsection{Promoter Sequence Identification and Transcription Factor Binding Site Identification}

The NCBI Entrez Gene database was used to search for eight NTC genes representing transportins and NupsNup98 (Gene ID 4928), Nup153 (Gene ID 9972), Nup214 (Gene ID 8021), Nup62 (Gene ID 23636), Nup188 (Gene ID 23511), Kpnb1 (Gene ID 3837), Tnpo1 (Gene ID 3842), and Crm1 (Xpo1, Gene ID 7514). Programs used to locate genes and regulatory sequences of transcription factor binding sites included FirstEF

(http://rulai.cshl.edu/tools/FirstEF/) for promoter site prediction; the Matrix Search for Transcription Factor Binding Sites (MATCH, http://www.gene-regulation.com/cgi-bin/pub/programs/match/bin/match.cgi); and JASPAR (http://jaspar.genereg.net/) that uses a curated transcription factor binding profile database.

\subsection{RNA Extraction from C6 Cell Line and cDNA Synthesis}

To evaluate rPer2 and rCrm1 gene expression total RNA was isolated from C6 cell lines using Arcturus Pico Pure RNA Isolation Kit (Life Technologies) at specific circadian time points after forskolin treatment. C6 cells for imaging were seeded $\left(10^{5}\right.$ cells/dish) in 35-mm tissue culture dishes and incubated in DMEM medium containing $10 \% \mathrm{FBS}$ at $37^{\circ} \mathrm{C}$ in $5 \% \mathrm{CO}_{2}$, overnight. The cells were washed twice with FM and treated with $20 \mu \mathrm{M}$ forskolin for 2 hrs. At the end of two hours, medium was exchanged with fresh FM. After the first 24-hr cycle, the total RNA was collected every 4 hours for 24 hours, starting at hour 0 . The isolated RNA concentration was measured using a nanodrop spectrophotometer (ThermoFisher Scientific), and quality was assessed on a 2.5\% agarose gel. The RNA was stored at $-80^{\circ} \mathrm{C}$ until used for cDNA synthesis. A total of $2 \mu \mathrm{g}$ of RNA for each time point was used for first strand synthesis using a high capacity cDNA synthesis kit from Applied Biosystems. The cDNA was synthesized at $37^{\circ} \mathrm{C}$ for 120 minutes followed by 5 -min incubation at $85^{\circ} \mathrm{C}$. The cDNA was stored at $-20^{\circ} \mathrm{C}$ until the next analysis.

\subsection{RNA Extraction from C6 Tumorspheres and cDNA Synthesis}

To address the question of whether the cancer stem cell genes rHes1 and rBmi1 are under clock regulation we performed qPCR analysis of their transcripts at 6-hr intervals for $48 \mathrm{hrs}$. A 2-hr, $20 \mu \mathrm{M}$ forskolin pulse that was used to synchronize mPer2 reporter gene rhythms in C6 cells before bioluminescence imaging was also used to synchronize spheres for total RNA extraction. The spheres (20 - 30 at each time point) were harvested starting 24 hrs after synchronization to avoid any acute effects of the forskolin pulse. The quality of RNA at each time point was checked for RNA integrity using gel electrophoresis. Only if the RNA was stable and no degradation was observed was it used for CDNA synthesis followed by qPCR analysis. As a positive control we used primers for Per2. RNA storage and cDNA synthesis was the same as for cell cultures.

\subsection{Quantitative Real-Time Polymerase Chain Reaction (qPCR)}

PCR primers used for this experiment are listed in Table 1. An initial DNA denaturation step at $95^{\circ} \mathrm{C}$ for 2 min was followed by 40 cycles of denaturation at $95^{\circ} \mathrm{C}$ for $30 \mathrm{~s}$, primer annealing at $58^{\circ} \mathrm{C}$ for $15 \mathrm{~s}$, and extension at $72^{\circ} \mathrm{C}$ for $30 \mathrm{~s}$. The primer specificity was confirmed by sequence searches in human and rat DNA databases (NCBI Primer search) and analyzed electrophoretically on agarose gels. The qPCR was performed using a Bio-Rad MJ Mini Opticon thermocycler (Bio-Rad) and Bio-Rad CFX Manager software. All PCR procedures were performed in duplicate in a volume of $20 \mu \mathrm{l}$ using 48-well optical-grade PCR plates and an optical sealing tape (USA Scientific). The C6 cell culture and tumorsphere results were normalized to $\beta$-actin expression ( $\Delta \mathrm{Ct}$ ). After normalization the transcript levels at each time point were calibrated to the 0 -hr time point $(\Delta \Delta \mathrm{Ct})$ and mRNA levels at each time point were calculated using the formula $2^{-\Delta \Delta \mathrm{Ct}}$.

\section{Results}

\subsection{Nuclear Import of Doxorubicin in C6 Glioma Cells Varies According to Circadian Phase}

We choose DOX for testing whether nuclear import is regulated by the circadian clock because of its inherent 
Table 1. Primer pairs used in qPCR analysis of cancer stem cell genes in C6 cell line and tumorspheres.

\begin{tabular}{ccc}
\hline Target & $5^{\prime} \rightarrow 3^{\prime}$ Sequence $\left(\right.$ orientation $\left.^{*}\right)$ & Product Size (bp) \\
\hline \multirow{2}{*}{ r $\beta$-actin } & CACCCGCGAGTACAACCTTCT (F) & 77 \\
& TATCGTCATCCATGGCGAACTGG (R) & 82 \\
rBmal1 & ACTGTCTAGGTGGAGGATTTTGG(F) & 100 \\
& CTGGTCACCTCAAAGCGACT(R) & 193 \\
rCrm1 & GAAGGAGCCCAGCAGAGAAT(F) & 94 \\
& TCTGCGAAAACTCCAAAATGGT(R) & \\
rHes1 & AGTCAGGGTAGGCCCTTTGA(F) & 182 \\
\end{tabular}

${ }^{*} \mathrm{~F}=$ forward, $\mathrm{R}=$ reverse.

fluorescence from its central anthracycline chromophore group [39], which makes it a popular research tool, and because it is used clinically for treatment of glioblastomas [40]-[44]. Additionally, DOX has also been used with the C6 cell line to study antitumor effects.

DOX nuclear import was tested with C6 cells at different phases of the circadian cycle after individual circadian cell clocks within the culture were synchronized with forskolin $(20 \mu \mathrm{M}$ for $2 \mathrm{hr})$. DOX was then delivered at seven time points. DOX accumulation in the nucleus over the 2 hrs after drug delivery was measured with a spinning disk confocal fluorescence microscope and non-laser light source to minimize any phototoxic effects on the cell. Integrated nuclear intensity measurements were made within an image plane passing through the cell body (Figure 1). Within the field-of-view used for measurements the average number of cells was $14.85 \pm 1.574$ (SD, range 12 to 17] across all circadian phases.

There was a nearly linear increase in nuclear uptake of DOX during most of the exposure time (Figure 1(a)). At the end of 2 hrs of imaging, the highest DOX nuclear signals were at the 0, 24, and 48-hr time points. An estimate of the rate of increase was provided by a linear regression that revealed a circadian rhythm in the fitted slope (Figure 1(b)). A point of saturation was observed for nuclear DOX uptake at the 24-hr point. The nuclear localization of DOX 2 hrs after application at the 24-hr phase is shown in Figure 1(c).

When the nuclear entry was analyzed to take into account individual time points from the 2-hr time series after DOX treatment, there was a similar circadian pattern with higher nuclear transport at 24 hours and lower transport at 36 hours (Figure 1(d) and Figure 1(e)). By 2 hours after DOX delivery, peaks in nuclear signal were observed 24 hours apart.

When the circadian rhythm in DOX nuclear uptake was compared with the rhythm in mPer2 gene expression, measured with a firefly luciferase reporter gene, the peak uptake preceded the mPER2:LUC peak expression by about 6 hours (Figure 2). The mPer2 clock gene expression was derived from a C6 culture expressing a reporter gene that generates a fusion protein of mPER2 and firefly luciferase under control by the mouse Per2 gene promoter. The mPer2-expressing cultures had a significant circadian period of $25.16 \mathrm{hrs}(\mathrm{p}<0.001)$ according to Lomb-Scargle periodogram (LS) analysis [45].

\subsection{Many NTC Genes Are Regulated by the Circadian Clock in Mouse Tissues}

We performed a screen for all clock-controlled genes that could be responsible for the rhythm in nuclear uptake. Because Nup98 and CRM1 proteins form a complex and mutated forms of Nup98 are present in leukemia cells we were particularly interested in any evidence of their circadian regulation through control of gene expression. We searched the CircaDB collection of cDNA microarray results for genes of known NTCs with circadian expression rhythms in mouse tissues and cell lines. Table 2 shows that genes encoding many of the important nuclear pore components and transporters have statistically significant circadian rhythms in gene expression (29 of 46 genes). Members of the import receptor family (e.g., importin $\beta 1$ ) and export receptors, including Crm1 and Nup98, are rhythmic in the tissues shown, suggesting that clock control of these genes is also possible in glioma cells. Several important Nups also showed circadian rhythms in their mRNA transcripts, providing evidence that the NPC is repaired or renewed daily. The liver was the most common site for circadian rhythms (18 

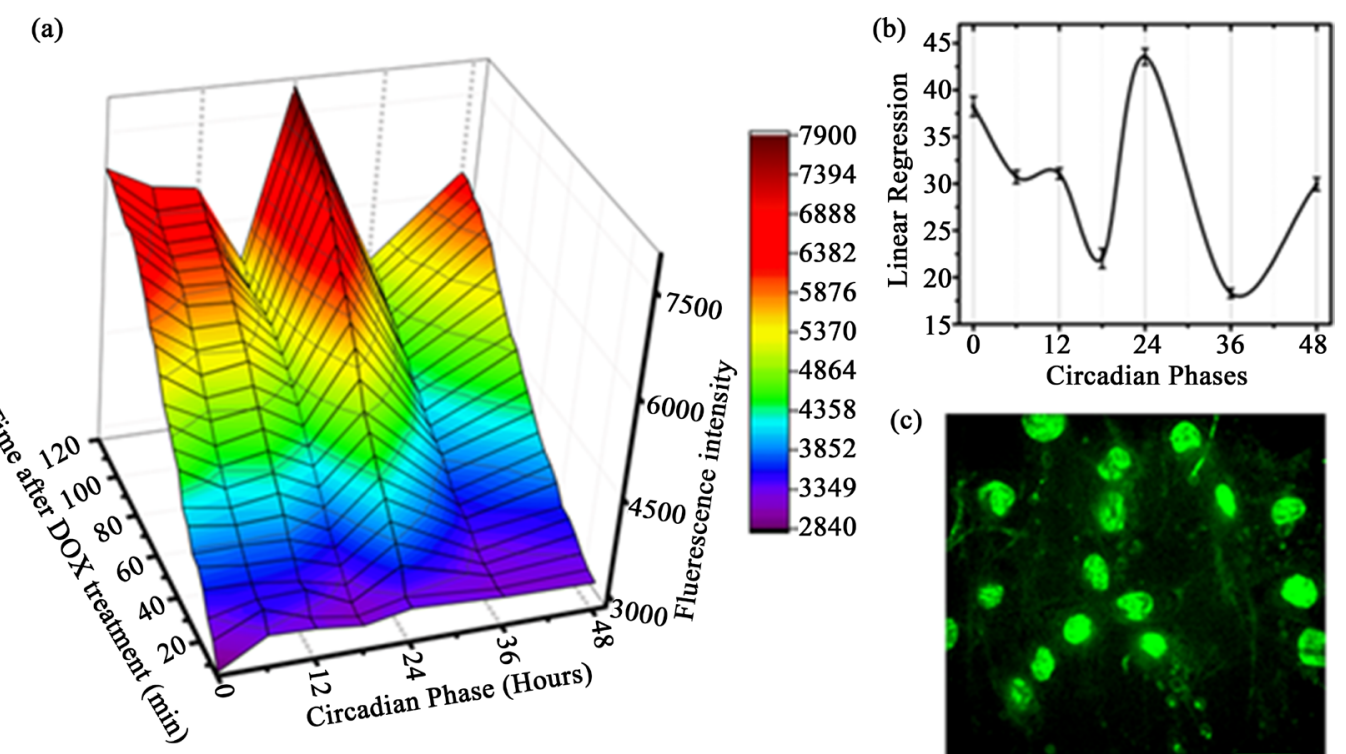

(c)

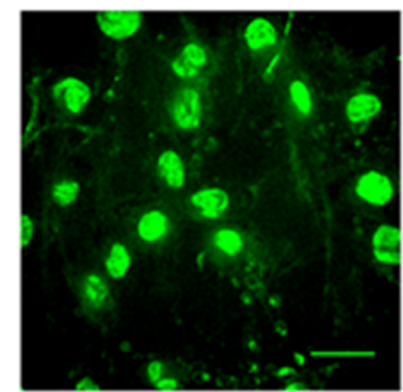

(d)

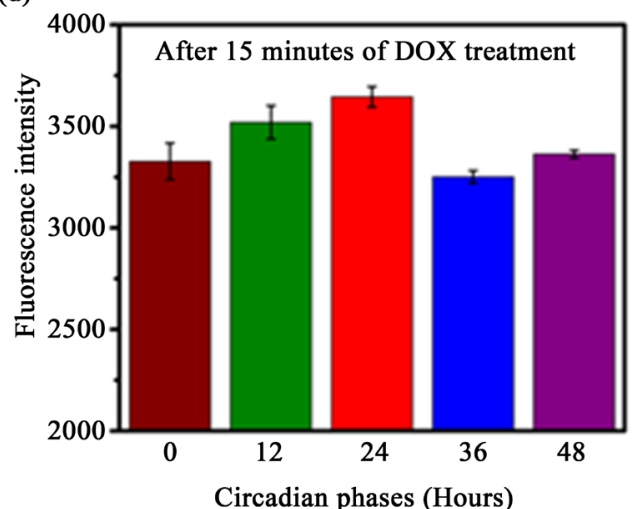

(e)

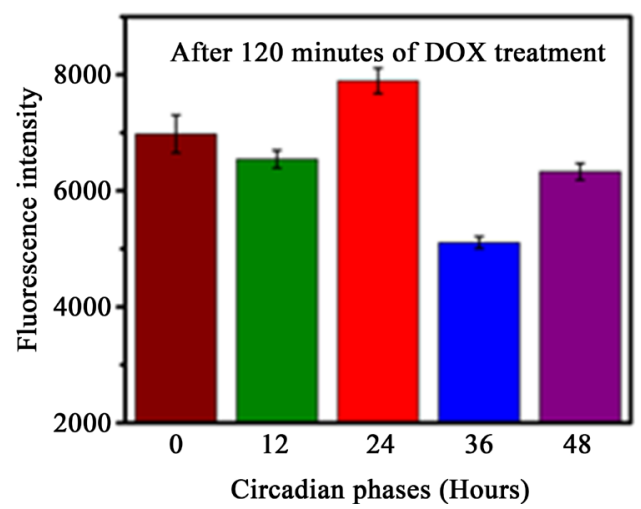

Figure 1. Circadian phase effects on DOX nuclear import rate. (a) The first 120 min of nuclear fluorescence from DOX that was applied to C6 cells at 7 different times across two consecutive 24-hr circadian cycles (phases 12 and 24 in the cycle repeat at 36 and 48). (b) Nuclear transport rates estimated by the slope of linear regressions to the increase in nuclear DOX fluorescence at different times. Error bars represent the error of the fit lines. (c) Fluorescence image of DOX nuclear localization 120 minutes after treatment at the $24-\mathrm{hr}$ phase. Scale bar $=10 \mu \mathrm{m}$. Average DOX intensity in nuclei 15 minutes after DOX treatment at different circadian phases (d) and after 120 minutes (e). Error bars are standard error of mean (SEM).

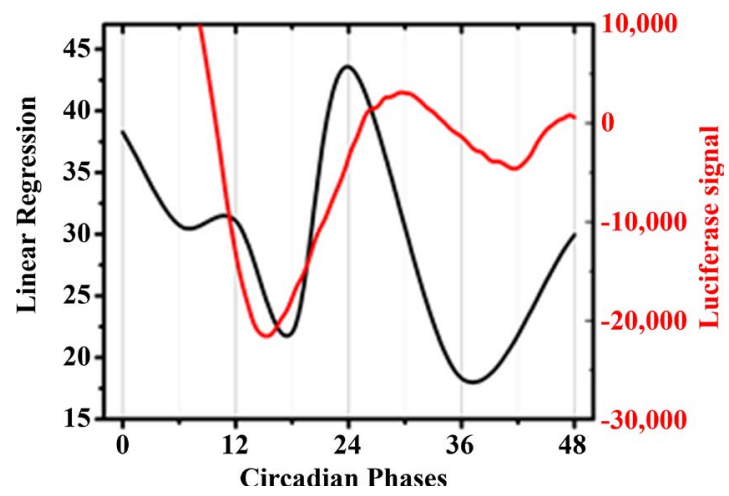

Figure 2. Comparing mPER2 protein and DOX nuclear import oscillations in C6 cells. The circadian rhythm in DOX nuclear signal (black) reaches a peak about 6 hours before the maximum mPER2:LUC fusion protein expression (red). Relative rate of nuclear entry is shown by linear regression slope as in Figure 1. 
Table 2. Circadian expression of mouse genes encoding nuclear transport components.

\begin{tabular}{|c|c|c|}
\hline Gene & Protein & Tissue or cell line* \\
\hline \multicolumn{3}{|c|}{ Import transport regulators or importins } \\
\hline Kpna1 & importin $\alpha 1$ & kidney, NIH 3T3 cell line \\
\hline Kpna2 & importin $\alpha 2$ & SCN, liver, skeletal muscle \\
\hline Kpna3 & importin $\alpha 3$ & kidney, heart \\
\hline Kpna4 & importin $\alpha 4$ & liver \\
\hline Kpnb1 & importin $\beta 1$ & liver, kidney, NIH 3 T3 cell line \\
\hline Kpna6 & importin $\alpha 6$ & liver \\
\hline Ipo7 & importin 7 & liver \\
\hline Ipo8 & importin 8 & ND \\
\hline Ipo9 & importin 9 & kidney, brown adipose tissue \\
\hline Ipo11 & importin 11 & liver, adrenal gland \\
\hline Ipo13 & importin 13 & lung \\
\hline Nutf2 & nuclear transport factor 2 & liver, brown adipose tissue \\
\hline Tnpo1 & transportin 1 & liver \\
\hline Tnpo2 & transportin 2 & ND \\
\hline Tnpo3 & transportin 3 & ND \\
\hline \multicolumn{3}{|c|}{ Export transport regulators or exportins } \\
\hline Xpo1 & Crm1 & SCN, liver, skeletal muscle, kidney \\
\hline Cse1l & Хро2 & kidney, brown adipose tissue \\
\hline Nup98 & nucleoporin 98 & Heart \\
\hline Nup214 & nucleoporin 214 & ND \\
\hline Nup88 & nucleoporin 88 & liver \\
\hline Gle1 & GLE1 RNA export mediator & ND \\
\hline \multicolumn{3}{|c|}{ Nuclear pore proteins or Nups } \\
\hline Nup54 & nucleoporin 54 & SCN \\
\hline Nup62 & nucleoporin 62 & liver, adrenal gland, heart \\
\hline Nupl1 & nucleoporin 58 & ND \\
\hline Nupl2 & nucleoporin-like 2 & liver \\
\hline Nup93 & nucleoporin 93 & ND \\
\hline Nup205 & nucleoporin 205 & liver, kidney, adrenal gland \\
\hline Nup188 & nucleoporin 188 & brown adipose tissue \\
\hline Nup155 & nucleoporin 155 & pituitary gland \\
\hline Nup35 & nucleoporin 35 & liver, adrenal gland, aorta \\
\hline Sec13 & nucleoporin 13 & kidney \\
\hline Nup133 & nucleoporin 133 & liver \\
\hline Nup37 & nucleoporin 37 & liver \\
\hline Nup43 & nucleoporin 43 & ND \\
\hline Nup85 & nucleoporin 85 & liver \\
\hline Nup160 & nucleoporin 160 & ND \\
\hline Nup96 & nucleoporin 96 & ND \\
\hline Nup107 & nucleoporin 107 & ND \\
\hline Seh1 & Seh1 & ND \\
\hline Pom121 & nuclear pore membrane protein 121 & ND \\
\hline Pom12112 & POM121 membrane glycoprotein-like 2 & ND \\
\hline Nup153 & nucleoporin 153 & ND \\
\hline Nup50 & nucleoporin 50 & SCN, liver \\
\hline Nup210 & nucleoporin 210 & ND \\
\hline Nup210l & nucleoporin 210-like & lung \\
\hline Ndc1 & NDC1 transmembrane nucleoporin & ND \\
\hline
\end{tabular}

${ }^{*}$ Tissues or cell lines that show significant rhythms with 19 to 29-hr period according to the Lomb-Scargle periodogram ( $\left.\mathrm{p}<0.05\right)$ as reported in CircaDB (circadian expression profiles database) http://circadb.hogeneschlab.org. ND = no circadian rhythm detected. Bold indicates circadian rhythm in the suprachiasmatic nucleus (SCN) of the hypothalamus. 
genes), and only 4 genes were rhythmic in the brain (SCN).

However, the high heterogeneity of cell types in the SCN might explain the lack of observable rhythms for some of the genes. Measurements of total mRNA expressed in the SCN may not detect a rhythm if the gene is expressed in circadian clock cells that operate at different phases relative to each other. In addition, a sufficient number of non-rhythmic cells that also express the candidate gene can obscure detection of a gene's circadian rhythm in clock cells.

Because of the importance of the Crm1 gene in cancer and the evidence of its control by the clock in the brain, we performed a promoter analysis to identify candidate circadian regulatory elements using the programs MATCH, JASPAR and AliBaba2. We found a canonical CACGTG E-box in the promoter, which is the element bound by the core clock proteins CLOCK and BMAL1 (Arntl). These proteins dimerize forming a transcription factor that rhythmically activates core clock genes, including Per2, and at least $10 \%$ of the genome. Nup98 was not selected for further study because it was not found to be rhythmic in the brain. The Nup98 promoter lacks the E-box, but we did identify a glucocorticoid receptor suggesting that the observed rhythm in the heart might be from regulation through the known circadian rhythm in glucocorticoid activity [46].

There are additional regulatory pathways that could explain the circadian rhythms described in Table 2. For example, we found that the promoter regions of Nup214, Nup188, and Nup153 contain transcription factorbinding sites for PAX-4, EVI-1, IRF, and AP-1 transcription factors that are significantly overrepresented in promoters of clock-controlled genes [47]. Also, we did not test for presence of other sequences that provide clock-control such as the D-box, which binds the clock gene DBP, or the RRE, which binds the retinoic acid-type receptors Rev-Erb and ROR that serve in the core clock mechanism [48]. Additional studies should determine whether these elements and the E-boxes function in circadian control of the rhythmic genes identified here.

\subsection{Crm1 Expression Exhibits a Circadian Oscillation in C6 Cells}

We focused on regulation of the rat Crm1 gene by performing a qRT-PCR study of C6 cells that were synchronized with forskolin as in the DOX procedure. Total RNA was harvested at 4-hr intervals for 24 hours after a 2-hr forskolin pulse. To identify the phase of the circadian oscillation in the culture we also measured Bmal1 expression. The cells were harvested starting 24 hours after synchronization to avoid any acute effects of the forskolin pulse. The rCrm1 transcripts showed peak expression about 4 hours after peak Bmal1 expression (Figure 3). This delay would be expected if rCrm1 is activated by the CLOCK/BMAL1 complex.

\subsection{Circadian Rhythms in C6 Tumorspheres are not in Phase with Oscillations in Hes1 or Bmi1 Gene Expression}

To evaluate whether the circadian clock controls genes that maintain GSCs in an undifferentiated state [49]-[51] we measured Hes1 (hairy and enhancer of split 1) and Bmi1 (B-cell-specific Moloney murine leukemia virus integration region 1) genes in forskolin-synchronized tumorspheres at intervals for up to $72 \mathrm{hrs}$. To minimize error from a single forskolin treatment, the experiment was completed in two sessions in which RNA was collected

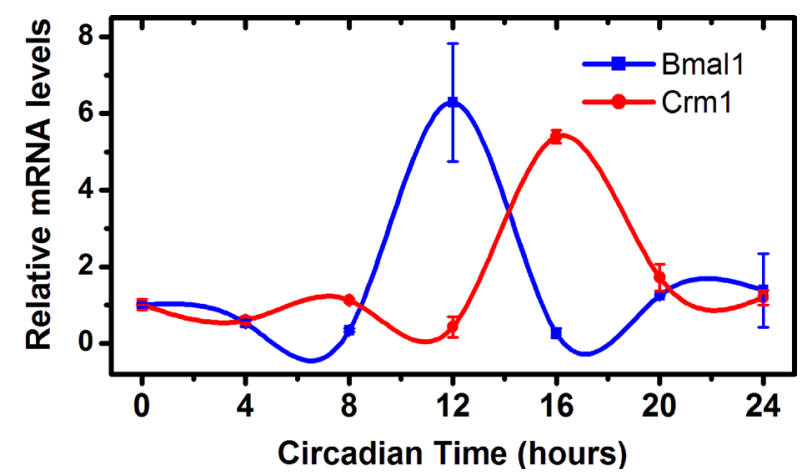

Figure 3. Oscillations in rCrm1 and rBmal1 gene expression in C6 cells. Peak rBmal1 levels precede rCrm1 activity and suggest that $\mathrm{rCrm} 1$ is under circadian clock control. Forskolin treatment was applied 24 hrs before time 0 to synchronize clock cells in the cultures. Shown are means of four samples \pm SEM and a spline fit to the data. 
from two sets of forskolin-treated tumorsphere cultures with the sampled time points alternating between the sets. The tumorspheres displayed the predicted near 24-hr oscillations in the transcript levels of rPer2 (Figure 4), in agreement with previously measured circadian rhythms in mPer2 expression in C6 cell cultures [9] and tumorspheres [23]. However, we did not observe a 24-hr oscillation in the transcript levels of rHes-1 or rBmi1, and both genes were expressed at frequencies outside the circadian range, suggesting that these stem cell maintenance genes operate without significant circadian clock control.

\section{Discussion}

\subsection{Circadian Rhythms in Nuclear Uptake}

The evidence of circadian clock-control of the nuclear pore complex and its associated proteins presented here has implications for the timing of drug delivery when treating gliomas. If the circadian phase of rhythms in tumors can be determined, then DOX could be delivered at the most effective phase for nuclear uptake, which was found here to occur when PER2 levels are increasing and about 12 hours from the rise in BMAL1 levels. This most effective phase occurred at roughly 24-hr intervals after forskolin was applied, suggesting that other agents that elevate cAMP levels, such as caffeine, might also synchronize this phase in the types of gliomas cells that express circadian rhythms. This insight could provide optimal phasing of treatments with DOX and similar anticancer agents. Additional studies are needed to also identify the circadian phase when DOX most effectively kills cancer cells. Evidence of circadian clock effects on DOX efficacy has been shown in a breast cancer cell line, although the role of circadian timing on nuclear uptake was not examined [52].

Numerous studies and clinical trials have demonstrated that toxicity, tolerability, and pharmacokinetic endpoints of chemotherapeutic drugs, including DOX, are strongly time dependent [53]. Being an intercalating agent, DOX needs to be maximally translocated into the nucleus to effectively induce toxicity in cancer cells. Based on previous studies of DOX nuclear translocation, its movement appears to depend on interaction with the $20 \mathrm{~S}$ proteasome subunit. Autofluorescence imaging of DOX nuclear entry has been linked to simultaneous
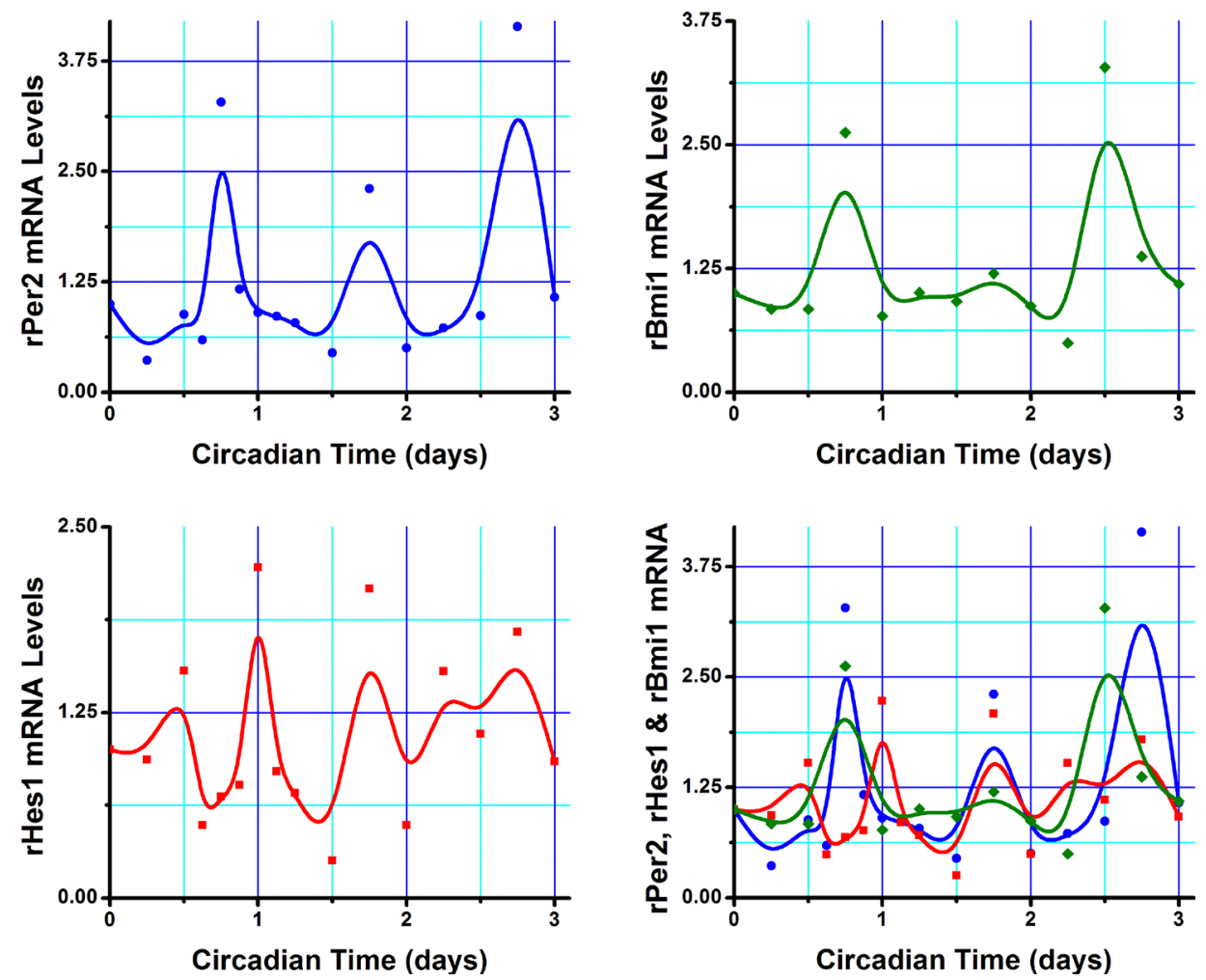

Figure 4. Oscillations in gene expression in C6 tumorspheres. C6 spheres exhibit circadian rPer2 expression (blue line) after forskolin treatment (at time 0). The stem cell genes rHes1 (red) and rBmi1 (green) are not under strong circadian control and their expression oscillates with frequencies that differ from the circadian rhythm in rPer2 expression. 
movement of the 20S proteasome subunit into the nucleus [35]-[37].

The observed rhythm in DOX accumulation could be explained if the 20S subunit is rhythmically translocated into the nucleus. Nuclear transport of the 26S proteasome, composed of a 20S core capped at one or both ends by 19S regulatory complexes [54], follows the classical nuclear transport pathways for import of its core particles or uses Blm10, a HEAT-like repeat protein structurally related to the NTC karyopherin $\beta$ (Tnpo1). Interestingly, Tnpo1 gene expression shows circadian rhythms in the SCN of mice under constant dark conditions [55] and throughout the brain. It is not yet known whether this rhythm is reflected in the protein's activity. The regulatory particles associated with the 26S proteasome structure use classical nuclear import mediated by a nuclear localization signal (NLS). The mechanism controlling export of the proteasome is not clear [56] [57].

Along with possible circadian modulation of the proteasome, the DOX results may be explained by clockdependent regulation of specific NTC genes. Based on several studies, $2 \%$ to $10 \%$ of mammalian genes are clock-controlled genes (CCGs) depending on the tissue, and many more genes are under indirect clock control by CCGs [58]-[61]. It was apparent that the circadian clock modulates the activity of many NTC genes, either directly or indirectly, according to the search of individual mouse genes in CircaDB that includes data from several studies of circadian transcript levels [59] [62]. Although these NTC genes are under clock control at the transcriptional level, particularly in the liver, it is not yet known whether this is true in glioma cells that have retained a functional circadian clock.

If human glioma cells contain their own circadian timing, they may benefit from this ability to anticipate predictable daily events. It could promote their survival and proliferation, like that of normal cells, by partitioning competing metabolic events into different times of day and by directing molecular processes to prepare for surges in nutrient availability following meals or the many daily cycles of cytokines, growth factors, and other hormones that impact cancer cells.

\subsection{Rhythms in Crm1 Gene Expression}

A second circadian property of C6 cells that could impact glioma treatments is the oscillation in Crm1 expression that occurs at a phase expected for a CCG driven by oscillations in BMAL1/CLOCK activity. Along with the canonical E-box of the Crm1 promoter region and its circadian expression in the SCN, this result indicates that drugs targeting CRM1 [63] [64], such as leptomycin B, could be more effective or better tolerated when applied at a particular time a day. A phase for optimal delivery may depend on whether CRM1 protein abundance is driven by its rhythm in expression. Furthermore, use of circadian timing to more effectively target CRM1 may also suppress activity by its partner Nup98 in leukemia.

CRM1 is a ubiquitous nuclear export receptor that binds to cargo proteins containing the hydrophobic nuclear export signal (NES). About 240 macromolecules are exported by CRM1 including tumor-suppressive proteins and oncoproteins [65]. Along with its cooperative interaction with mutated Nup98 protein, the hyperactivity of CRM1 in cancer cells may accelerate export of tumor suppressors into the cytoplasm, thereby increasing cancer proliferation [63]. Of course, CRM1 might export protein complexes with DOX or other drugs, and a rhythm in Crm1 activity could also explain the rhythm in DOX accumulation we observed.

CRM1, along with other common nuclear transport receptors, serves in nucleocytoplasmic shuttling of circadian clock proteins [66], a major feature in the molecular timing mechanism [67]. Disrupted circadian rhythms can lead to deregulated cell proliferation and possibly tumorigenesis [22] [68]. A regular circadian schedule and proper functioning of clock components appears to provide protection from some cancers. The timing of clock protein entry, residence time in the nucleus, and export of these proteins and their mRNA are important for circadian rhythms of the cell [69]. Most of the clock proteins contain NLS and NES sequences for receptor mediated nuclear transport [66] [70] [71], and depend on CRM1 as a major player in nuclear export of clock proteins [72] [73].

A most interesting result from this study is the identification of Crm1 oscillations in C6 cell cultures. Many of the circadian rhythms listed in Table 2 are in tissue harvested at different phases of the circadian cycle. Some of these oscillations may be driven by circadian clocks located outside the tissue that was collected. Only two of the NTC gene oscillations were found in a cell culture, which are rhythms produced by circadian clocks endogenous to those cells. By identifying a significant oscillation in Crm1 gene expression in C6 cells we have provided strong evidence that it is driven by the circadian clock known to exist in these cells, suggesting that Crm1 activity rhythms are present in other gliomas. 


\subsection{The Circadian Clock in Glioma Stem Cells}

A third circadian property of C6 cells indicating additional options for glioma treatment is the circadian rhythm in the GSC population. We previously described circadian rhythms in C6 tumorspheres, which are enriched detached cultures of GSCs and progenitor cells [23]. Although lacking a circulatory system and stromal cells, tumorspheres are a model of tumor behavior under controlled conditions not achievable in animal studies, revealing what GSCs are capable of, but not necessarily what occurs in gliomas.

As a way to study cancer cell proliferation or differentiation, tumorspheres can also reveal basic molecular processes regulating other stem cells and development because of shared stem cell maintenance genes. It is also clear that nuclear pore proteins have a larger role than just nucleocytoplasmic transport and are fundamental players in embryonic stem cells as well [74]-[76]. For example, cell type-specific Nup133 expression is enhanced during particular developmental stages [77], and Nup153 suppresses developmental genes in embryonic stem cells [78].

The role of circadian rhythms in cancer is linked to their role in the differentiation of stem cells and progenitor cells. The circadian clock emerges most clearly as neural stem cells differentiate [79]-[81]. To determine whether circadian clock control extends to genes that regulate stem cell proliferation and suppress differentiation, we measured transcript levels of the rat Hes1 and Bmi1 genes in C6 tumorspheres [49] [51] [82]. The oscillations in their expression did not match the circadian oscillation in Per2 gene activity, indicating that some stem cell regulation continues through higher frequency signals than those found in the circadian clock. Because of the linkage between Nups and embryonic stem cells additional studies should examine other NTC genes in GSCs and determine whether they too undergo rapid oscillations instead of circadian control. Nevertheless, the tumorsphere results did confirm that cultures enriched in GSCs express circadian rhythms in clock gene expression and so provide opportunities for exploiting phase-dependent differences in drug effects on these persistent cancer cells.

\section{Conclusion}

A challenge is to find inhibitors of Crm1, Hes1, or Bmi1 that have minimal effects on BMAL1 and CLOCK expression. Alternatively, agents that induce Per2 but not BMAL1 could be effective by increasing the amplitude of circadian rhythms in those cancers that would respond to improved circadian timing, and the results shown here suggest that they could be delivered at a phase that would not affect Crm1. Furthermore, drugs currently used to suppress Crm1 or Notch pathway inhibitors might be given at a phase that avoids Per2 suppression to preserve the clock while still remaining effective.

\section{Acknowledgements}

This paper is supported in part by the BGSU J.P. Scott Center for Neuroscience, Mind, and Behavior. We thank Cameron McLaughlin for editorial help with the manuscript.

\section{References}

[1] Blumenthal, R.D., Waskewich, C., Goldenberg, D.M., Lew, W., Flefleh, C. and Burton, J. (2001) Chronotherapy and Chronotoxicity of the Cyclooxygenase-2 Inhibitor, Celecoxib, in Athymic Mice Bearing Human Breast Cancer Xenografts. Clincal Cancer Research, 7, 3178-3185.

[2] Hrushesky, W.J., Lester, B. and Lannin, D. (1999) Circadian Coordination of Cancer Growth and Metastatic Spread. International Journal of Cancer, 83, 365-373. http://dx.doi.org/10.1002/(SICI)1097-0215(19991029)83:3<365::AID-IJC12>3.3.CO;2-W

[3] Levi, F. (2001) Circadian Chronotherapy for Human Cancers. The Lancet Oncology, 2, 307-315. http://dx.doi.org/10.1016/S1470-2045(00)00326-0

[4] Ortiz-Tudela, E., Mteyrek, A., Ballesta, A., Innominato, P.F. and Levi, F. (2013) Cancer Chronotherapeutics: Experimental, Theoretical, and Clinical Aspects. Handbook of Experimental Pharmacology, 217, 261-288. http://dx.doi.org/10.1007/978-3-642-25950-0 11

[5] Kondratov, R. (2014) Circadian Clock and Cancer Therapy: An Unexpected Journey. Annals of Medicine, 46, 189-190. http://dx.doi.org/10.3109/07853890.2014.920213

[6] Izumo, M., Sato, T.R., Straume, M. and Johnson, C.H. (2006) Quantitative Analyses of Circadian Gene Expression in Mammalian Cell Cultures. PLoS Computational Biology, 2, e136. http://dx.doi.org/10.1371/journal.pcbi.0020136 
[7] Pendergast, J.S., Yeom, M., Reyes, B.A., Ohmiya, Y. and Yamazaki, S. (2010) Disconnected Circadian and Cell Cycles in a Tumor-Driven Cell Line. Communicative \& Integrative Biology, 3, 536-539. http://dx.doi.org/10.4161/cib.3.6.12841

[8] Yamanaka, I., Koinuma, S., Shigeyoshi, Y., Uchiyama, Y. and Yagita, K. (2007) Presence of Robust Circadian Clock Oscillation under Constitutive Over-Expression of mCry1 in Rat-1 Fibroblasts. FEBS Letters, 581, 4098-4102. http://dx.doi.org/10.1016/j.febslet.2007.07.053

[9] Fujioka, A., Takashima, N. and Shigeyoshi, Y. (2006) Circadian Rhythm Generation in a Glioma Cell Line. Biochemical and Biophysical Research Communications, 346, 169-174. http://dx.doi.org/10.1016/j.bbrc.2006.05.094

[10] Rana, S. and Mahmood, S. (2010) Circadian Rhythm and Its Role in Malignancy. Journal of Circadian Rhythms, 8, 3. http://dx.doi.org/10.1186/1740-3391-8-3

[11] Zhao, N., Tang, H., Yang, K. and Chen, D. (2013) Circadian Rhythm Characteristics of Oral Squamous Cell Carcinoma Growth in an Orthotopic Xenograft Model. OncoTargets and Therapy, 6, 41-46. http://dx.doi.org/10.2147/OTT.S39955

[12] Wu, A., Oh, S., Wiesner, S.M., Ericson, K., Chen, L., Hall, W.A., Champoux, P.E., Low, W.C. and Ohlfest, J.R. (2008) Persistence of CD133+ Cells in Human and Mouse Glioma Cell Lines: Detailed Characterization of GL261 Glioma Cells with Cancer Stem Cell-Like Properties. Stem Cells and Development, 17, 173-184. http://dx.doi.org/10.1089/scd.2007.0133

[13] Puram, R.V., Kowalczyk, M.S., de Boer, C.G., Schneider, R.K., Miller, P.G., McConkey, M., Tothova, Z., Tejero, H., Heckl, D., Jaras, M., Chen, M.C., Li, H., Tamayo, A., Cowley, G.S., Rozenblatt-Rosen, O., Al-Shahrour, F., Regev, A. and Ebert, B.L. (2016) Core Circadian Clock Genes Regulate Leukemia Stem Cells in AML. Cell, 165, 303-316. http://dx.doi.org/10.1016/j.cell.2016.03.015

[14] Filipski, E., King, V.M., Li, X., Granda, T.G., Mormont, M.C., Claustrat, B., Hastings, M.H. and Levi, F. (2003) Disruption of Circadian Coordination Accelerates Malignant Growth in Mice. Pathologie Biologie (Paris), 51, $216-219$. http://dx.doi.org/10.1016/S0369-8114(03)00034-8

[15] Filipski, E., Li, X.M. and Levi, F. (2006) Disruption of Circadian Coordination and Malignant Growth. Cancer Causes \& Control, 17, 509-514. http://dx.doi.org/10.1007/s10552-005-9007-4

[16] Gery, S., Komatsu, N., Baldjyan, L., Yu, A., Koo, D. and Koeffler, H.P. (2006) The Circadian Gene Per1 Plays an Important Role in Cell Growth and DNA Damage Control in Human Cancer Cells. Molecular Cell, 22, 375-382. http://dx.doi.org/10.1016/j.molcel.2006.03.038

[17] Xiang, S., Mao, L., Duplessis, T., Yuan, L., Dauchy, R., Dauchy, E., Blask, D.E., Frasch, T. and Hill, S.M. (2012) Oscillation of Clock and Clock Controlled Genes Induced by Serum Shock in Human Breast Epithelial and Breast Cancer Cells: Regulation by Melatonin. Breast Cancer (Auckl), 6, 137-150.

[18] Antoch, M.P., Gorbacheva, V.Y., Vykhovanets, O., Toshkov, I.A., Kondratov, R.V., Kondratova, A.A., Lee, C. and Nikitin, A.Y. (2008) Disruption of the Circadian Clock Due to the Clock Mutation Has Discrete Effects on Aging and Carcinogenesis. Cell Cycle, 7, 1197-1204. http://dx.doi.org/10.4161/cc.7.9.5886

[19] Ozturk, N., Lee, J.H., Gaddameedhi, S. and Sancar, A. (2009) Loss of Cryptochrome Reduces Cancer Risk in p53 Mutant Mice. Proceedings of the National Academy of Sciences of the United States of America, 106, 2841-2846. http://dx.doi.org/10.1073/pnas.0813028106

[20] Elshazley, M., Sato, M., Hase, T., Yamashita, R., Yoshida, K., Toyokuni, S., Ishiguro, F., Osada, H., Sekido, Y., Yokoi, K., Usami, N., Shames, D.S., Kondo, M., Gazdar, A.F., Minna, J.D. and Hasegawa, Y. (2012) The Circadian Clock Gene BMAL1 Is a Novel Therapeutic Target for Malignant Pleural Mesothelioma. International Journal of Cancer, 131, 2820-2831. http://dx.doi.org/10.1002/ijc.27598

[21] Kelleher, F.C., Rao, A. and Maguire, A. (2014) Circadian Molecular Clocks and Cancer. Cancer Letters, 342, 9-18. http://dx.doi.org/10.1016/j.canlet.2013.09.040

[22] Hrushesky, W.J., Grutsch, J., Wood, P., Yang, X., Oh, E.Y., Ansell, C., Kidder, S., Ferrans, C., Quiton, D.F., Reynolds, J., Du-Quiton, J., Levin, R., Lis, C. and Braun, D. (2009) Circadian Clock Manipulation for Cancer Prevention and Control and the Relief of Cancer Symptoms. Integrative Cancer Therapies, 8, 387-397. http://dx.doi.org/10.1177/1534735409352086

[23] Sharma, V.P., Anderson, N.T. and Geusz, M.E. (2014) Circadian Properties of Cancer Stem Cells in Glioma Cell Cultures and Tumorspheres. Cancer Letters, 345, 65-74. http://dx.doi.org/10.1016/j.canlet.2013.11.009

[24] Xu, S. and Powers, M.A. (2009) Nuclear Pore Proteins and Cancer. Seminars in Cell \& Developmental Biology, 20, 620-630. http://dx.doi.org/10.1016/j.semcdb.2009.03.003

[25] Turner, J.G., Dawson, J., Cubitt, C.L., Baz, R. and Sullivan, D.M. (2014) Inhibition of CRM1-Dependent Nuclear Export Sensitizes Malignant Cells to Cytotoxic and Targeted Agents. Seminars in Cancer Biology, 27, 62-73. http://dx.doi.org/10.1016/j.semcancer.2014.03.001 
[26] Shen, A., Wang, Y., Zhao, Y., Zou, L., Sun, L. and Cheng, C. (2009) Expression of CRM1 in Human Gliomas and Its Significance in p27 Expression and Clinical Prognosis. Neurosurgery, 65, 153-159. http://dx.doi.org/10.1227/01.neu.0000348550.47441.4b

[27] Gough, S.M., Slape, C.I. and Aplan, P.D. (2011) NUP98 Gene Fusions and Hematopoietic Malignancies: Common Themes and New Biologic Insights. Blood, 118, 6247-6257. http://dx.doi.org/10.1182/blood-2011-07-328880

[28] Qiu, J.J., Zeisig, B.B., Li, S., Liu, W., Chu, H., Song, Y., Giordano, A., Schwaller, J., Gronemeyer, H., Dong, S. and So, C.W. (2015) Critical Role of Retinoid/Rexinoid Signaling in Mediating Transformation and Therapeutic Response of NUP98-RARG Leukemia. Leukemia, 29, 1153-1162. http://dx.doi.org/10.1038/leu.2014.334

[29] Deveau, A.P., Forrester, A.M., Coombs, A.J., Wagner, G.S., Grabher, C., Chute, I.C., Leger, D., Mingay, M., Alexe, G., Rajan, V., Liwski, R., Hirst, M., Steigmaier, K., Lewis, S.M., Look, A.T. and Berman, J.N. (2015) Epigenetic Therapy Restores Normal Hematopoiesis in a Zebrafish Model of NUP98-HOXA9-Induced Myeloid Disease. Leukemia, 29, 2086-2097. http://dx.doi.org/10.1038/leu.2015.126

[30] Humeniuk, R., Koller, R., Bies, J., Aplan, P. and Wolff, L. (2014) Brief Report: Loss of p15Ink4b Accelerates Development of Myeloid Neoplasms in Nup98-HoxD13 Transgenic Mice. Stem Cells, 32, 1361-1366. http://dx.doi.org/10.1002/stem.1635

[31] Zhu, H.H., Zhao, X.S., Qin, Y.Z., Lai, Y.Y. and Jiang, H. (2016) B-Cell Acute Lymphoblastic Leukemia Associated with SET-NUP214 Rearrangement: A Case Report and Review of the Literature. Oncology Letters, 11, 2644-2650. http://dx.doi.org/10.3892/ol.2016.4260

[32] Sandahl, J.D., Coenen, E.A., Forestier, E., Harbott, J., Johansson, B., Kerndrup, G., Adachi, S., Auvrignon, A., Beverloo, H.B., Cayuela, J.M., Chilton, L., Fornerod, M., de Haas, V., Harrison, C.J., Inaba, H., Kaspers, G.J., Liang, D.C., Locatelli, F., Masetti, R., Perot, C., Raimondi, S.C., Reinhardt, K., Tomizawa, D., von Neuhoff, N., Zecca, M., Zwaan, C.M., van den Heuvel-Eibrink, M.M. and Hasle, H. (2014) T(6;9)(P22;Q34)/DEK-NUP214-Rearranged Pediatric Myeloid Leukemia: An International Study of 62 Patients. Haematologica, 99, 865-872. http://dx.doi.org/10.3324/haematol.2013.098517

[33] Weiss, R.B. (1992) The Anthracyclines: Will We Ever Find a Better Doxorubicin? Seminars in Oncology, 19, 670-686.

[34] Keizer, H.G., Pinedo, H.M., Schuurhuis, G.J. and Joenje, H. (1990) Doxorubicin (Adriamycin): A Critical Review of Free Radical-Dependent Mechanisms of Cytotoxicity. Pharmacology \& Therapeutics, 47, $219-231$. http://dx.doi.org/10.1016/0163-7258(90)90088-J

[35] Minotti, G., Menna, P., Salvatorelli, E., Cairo, G. and Gianni, L. (2004) Anthracyclines: Molecular Advances and Pharmacologic Developments in Antitumor Activity and Cardiotoxicity. Pharmacological Reviews, 56, 185-229. http://dx.doi.org/10.1124/pr.56.2.6

[36] Carvalho, C., Santos, R.X., Cardoso, S., Correia, S., Oliveira, P.J., Santos, M.S. and Moreira, P.I. (2009) Doxorubicin: The Good, the Bad and the Ugly Effect. Current Medicinal Chemistry, 16, 3267-3285. http://dx.doi.org/10.2174/092986709788803312

[37] Kiyomiya, K., Matsuo, S. and Kurebe, M. (2001) Mechanism of Specific Nuclear Transport of Adriamycin: The Mode of Nuclear Translocation of Adriamycin-Proteasome Complex. Cancer Research, 61, 2467-2471.

[38] Hiler, D.J., Bhattacherjee, A., Yamazaki, S., Tei, H. and Geusz, M.E. (2008) Circadian mPer1 Gene Expression in Mesencephalic Trigeminal Nucleus Cultures. Brain Research, 1214, 84-93. http://dx.doi.org/10.1016/j.brainres.2008.03.041

[39] Mohan, P. and Rapoport, N. (2010) Doxorubicin as a Molecular Nanotheranostic Agent: Effect of Doxorubicin Encapsulation in Micelles or Nanoemulsions on the Ultrasound-Mediated Intracellular Delivery and Nuclear Trafficking. Molecular Pharmaceutics, 7, 1959-1973. http://dx.doi.org/10.1021/mp100269f

[40] Liu, S., Guo, Y., Huang, R., Li, J., Huang, S., Kuang, Y., Han, L. and Jiang, C. (2012) Gene and Doxorubicin Co-Delivery System for Targeting Therapy of Glioma. Biomaterials, 33, 4907-4916. http://dx.doi.org/10.1016/j.biomaterials.2012.03.031

[41] Baltes, S., Freund, I., Lewis, A.L., Nolte, I. and Brinker, T. (2010) Doxorubicin and Irinotecan Drug-Eluting Beads for Treatment of Glioma: A Pilot Study in a Rat Model. Journal of Materials Science: Materials in Medicine, 21, 13931402. http://dx.doi.org/10.1007/s10856-009-3803-4

[42] Glas, M., Koch, H., Hirschmann, B., Jauch, T., Steinbrecher, A., Herrlinger, U., Bogdahn, U. and Hau, P. (2007) Pegylated Liposomal Doxorubicin in Recurrent Malignant Glioma: Analysis of a Case Series. Oncology, 72, 302-307. http://dx.doi.org/10.1159/000113052

[43] Hau, P., Fabel, K., Baumgart, U., Rummele, P., Grauer, O., Bock, A., Dietmaier, C., Dietmaier, W., Dietrich, J., Dudel, C., Hubner, F., Jauch, T., Drechsel, E., Kleiter, I., Wismeth, C., Zellner, A., Brawanski, A., Steinbrecher, A., Marienhagen, J. and Bogdahn, U. (2004) Pegylated Liposomal Doxorubicin-Efficacy in Patients with Recurrent High-Grade Glioma. Cancer, 100, 1199-1207. http://dx.doi.org/10.1002/cncr.20073 
[44] Darling, J.L. and Thomas, D.G. (2001) Response of Short-Term Cultures Derived from Human Malignant Glioma to Aziridinylbenzoquinone, Etoposide and Doxorubicin: An in Vitro Phase II Trial. Anticancer Drugs, 12, 753-760. http://dx.doi.org/10.1097/00001813-200110000-00007

[45] Van Dongen, H.P., Olofsen, E., VanHartevelt, J.H. and Kruyt, E.W. (1999) Searching for Biological Rhythms: Peak Detection in the Periodogram of Unequally Spaced Data. Journal of Biological Rhythms, 14, 617-620. http://dx.doi.org/10.1177/074873099129000984

[46] Nader, N., Chrousos, G.P. and Kino, T. (2009) Circadian Rhythm Transcription Factor CLOCK Regulates the Transcriptional Activity of the Glucocorticoid Receptor by Acetylating Its Hinge Region Lysine Cluster: Potential Physiological Implications. The FASEB Journal, 23, 1572-1583. http://dx.doi.org/10.1096/fj.08-117697

[47] Bozek, K., Relogio, A., Kielbasa, S.M., Heine, M., Dame, C., Kramer, A. and Herzel, H. (2009) Regulation of ClockControlled Genes in Mammals. PLoS ONE, 4, e4882. http://dx.doi.org/10.1371/journal.pone.0004882

[48] Ukai-Tadenuma, M., Yamada, R.G., Xu, H., Ripperger, J.A., Liu, A.C. and Ueda, H.R. (2011) Delay in Feedback Repression by Cryptochrome 1 Is Required for Circadian Clock Function. Cell, 144, 268-281. http://dx.doi.org/10.1016/j.cell.2010.12.019

[49] Brennan, C., Momota, H., Hambardzumyan, D., Ozawa, T., Tandon, A., Pedraza, A. and Holland, E. (2009) Glioblastoma Subclasses Can Be Defined by Activity among Signal Transduction Pathways and Associated Genomic Alterations. PLoS ONE, 4, e7752. http://dx.doi.org/10.1371/journal.pone.0007752

[50] Zhang, X.P., Zheng, G., Zou, L., Liu, H.L., Hou, L.H., Zhou, P., Yin, D.D., Zheng, Q.J., Liang, L., Zhang, S.Z., Feng, L., Yao, L.B., Yang, A.G., Han, H. and Chen, J.Y. (2008) Notch Activation Promotes Cell Proliferation and the Formation of Neural Stem Cell-Like Colonies in Human Glioma Cells. Molecular and Cellular Biochemistry, 307, 101108. http://dx.doi.org/10.1007/s11010-007-9589-0

[51] Katoh, Y. and Katoh, M. (2009) Hedgehog Target Genes: Mechanisms of Carcinogenesis Induced by Aberrant Hedgehog Signaling Activation. Current Molecular Medicine, 9, 873-886. http://dx.doi.org/10.2174/156652409789105570

[52] Mitchell, M.I. and Engelbrecht, A.M. (2015) Circadian Rhythms and Breast Cancer: The Role of Per2 in DoxorubicinInduced Cell Death. Journal of Toxicology, 2015, Article ID: 392360. http://dx.doi.org/10.1155/2015/392360

[53] Granda, T.G., Filipski, E., D’Attino, R.M., Vrignaud, P., Anjo, A., Bissery, M.C. and Levi, F. (2001) Experimental Chronotherapy of Mouse Mammary Adenocarcinoma MA13/C with Docetaxel and Doxorubicin as Single Agents and in Combination. Cancer Research, 61, 1996-2001.

[54] Voges, D., Zwickl, P. and Baumeister, W. (1999) The 26S Proteasome: A Molecular Machine Designed for Controlled Proteolysis. Annual Review of Biochemistry, 68, 1015-1068. http://dx.doi.org/10.1146/annurev.biochem.68.1.1015

[55] Sato, M., Mizoro, Y., Atobe, Y., Fujimoto, Y., Yamaguchi, Y., Fustin, J.M., Doi, M. and Okamura, H. (2011) Transportin 1 in the Mouse Brain: Appearance in Regions of Neurogenesis, Cerebrospinal Fluid Production/Sensing, and Circadian Clock. The Journal of Comparative Neurology, 519, 1770-1780. http://dx.doi.org/10.1002/cne.22600

[56] Burcoglu, J., Zhao, L. and Enenkel, C. (2015) Nuclear Import of Yeast Proteasomes. Cells, 4, 387-405. http://dx.doi.org/10.3390/cells4030387

[57] Enenkel, C. (2014) Nuclear Transport of Yeast Proteasomes. Biomolecules, 4, 940-955. http://dx.doi.org/10.3390/biom4040940

[58] Kornmann, B., Preitner, N., Rifat, D., Fleury-Olela, F. and Schibler, U. (2001) Analysis of Circadian Liver Gene Expression by ADDER, a Highly Sensitive Method for the Display of Differentially Expressed mRNAs. Nucleic Acids Research, 29, e51. http://dx.doi.org/10.1093/nar/29.11.e51

[59] Panda, S., Antoch, M.P., Miller, B.H., Su, A.I., Schook, A.B., Straume, M., Schultz, P.G., Kay, S.A., Takahashi, J.S. and Hogenesch, J.B. (2002) Coordinated Transcription of Key Pathways in the Mouse by the Circadian Clock. Cell, 109, 307-320. http://dx.doi.org/10.1016/S0092-8674(02)00722-5

[60] Storch, K.F., Lipan, O., Leykin, I., Viswanathan, N., Davis, F.C., Wong, W.H. and Weitz, C.J. (2002) Extensive and Divergent Circadian Gene Expression in Liver and Heart. Nature, 417, 78-83. http://dx.doi.org/10.1038/nature744

[61] Storch, K.F., Paz, C., Signorovitch, J., Raviola, E., Pawlyk, B., Li, T. and Weitz, C.J. (2007) Physiological Importance of a Circadian Clock outside the Suprachiasmatic Nucleus. Cold Spring Harbor Symposia on Quantitative Biology, 72, 307-318. http://dx.doi.org/10.1101/sqb.2007.72.053

[62] Hughes, M.E., DiTacchio, L., Hayes, K.R., Vollmers, C., Pulivarthy, S., Baggs, J.E., Panda, S. and Hogenesch, J.B. (2009) Harmonics of Circadian Gene Transcription in Mammals. PLoS Genetics, 5, e1000442. http://dx.doi.org/10.1371/journal.pgen.1000442

[63] Tan, D.S., Bedard, P.L., Kuruvilla, J., Siu, L.L. and Razak, A.R. (2014) Promising SINEs for Embargoing NuclearCytoplasmic Export as an Anticancer Strategy. Cancer Discovery, 4, 527-537. http://dx.doi.org/10.1158/2159-8290.CD-13-1005 
[64] Dickmanns, A., Monecke, T. and Ficner, R. (2015) Structural Basis of Targeting the Exportin CRM1 in Cancer. Cells, 4, 538-568. http://dx.doi.org/10.3390/cells4030538

[65] Xu, D., Farmer, A., Collett, G., Grishin, N.V. and Chook, Y.M. (2012) Sequence and Structural Analyses of Nuclear Export Signals in the NESdb Database. Molecular Biology of the Cell, 23, 3677-3693. http://dx.doi.org/10.1091/mbc.E12-01-0046

[66] Kwon, I., Lee, J., Chang, S.H., Jung, N.C., Lee, B.J., Son, G.H., Kim, K. and Lee, K.H. (2006) BMAL1 Shuttling Controls Transactivation and Degradation of the CLOCK/BMAL1 Heterodimer. Molecular and Cellular Biology, 26, 7318-7330. http://dx.doi.org/10.1128/MCB.00337-06

[67] Cermakian, N. and Sassone-Corsi, P. (2000) Multilevel Regulation of the Circadian Clock. Nature Reviews Molecular Cell Biology, 1, 59-67. http://dx.doi.org/10.1038/35036078

[68] Savvidis, C. and Koutsilieris, M. (2012) Circadian Rhythm Disruption in Cancer Biology. Molecular Medicine, 18, 1249-1260.

[69] Tamanini, F., Yagita, K., Okamura, H. and van der Horst, G.T. (2005) Nucleocytoplasmic Shuttling of Clock Proteins. Methods in Enzymology, 393, 418-435. http://dx.doi.org/10.1016/S0076-6879(05)93020-6

[70] Miyazaki, K., Mesaki, M. and Ishida, N. (2001) Nuclear Entry Mechanism of Rat PER2 (rPER2): Role of rPER2 in Nuclear Localization of CRY Protein. Molecular and Cellular Biology, 21, 6651-6659. http://dx.doi.org/10.1128/MCB.21.19.6651-6659.2001

[71] Sakakida, Y., Miyamoto, Y., Nagoshi, E., Akashi, M., Nakamura, T.J., Mamine, T., Kasahara, M., Minami, Y., Yoneda, Y. and Takumi, T. (2005) Importin Alpha/Beta Mediates Nuclear Transport of a Mammalian Circadian Clock Component, mCRY2, Together with mPER2, through a Bipartite Nuclear Localization Signal. The Journal of Biological Chemistry, 280, 13272-13278. http://dx.doi.org/10.1074/jbc.M413236200

[72] Yagita, K., Tamanini, F., Yasuda, M., Hoeijmakers, J.H., van der Horst, G.T. and Okamura, H. (2002) Nucleocytoplasmic Shuttling and mCRY-Dependent Inhibition of Ubiquitylation of the mPER2 Clock Protein. The EMBO Journal, 21, 1301-1314. http://dx.doi.org/10.1093/emboj/21.6.1301

[73] Vielhaber, E.L., Duricka, D., Ullman, K.S. and Virshup, D.M. (2001) Nuclear Export of Mammalian PERIOD Proteins. The Journal of Biological Chemistry, 276, 45921-45927. http://dx.doi.org/10.1074/jbc.M107726200

[74] Liang, Y., Franks, T.M., Marchetto, M.C., Gage, F.H. and Hetzer, M.W. (2013) Dynamic Association of NUP98 with the Human Genome. PLoS Genetics, 9, e1003308. http://dx.doi.org/10.1371/journal.pgen.1003308

[75] Sangel, P., Oka, M. and Yoneda, Y. (2014) The Role of Importin-Betas in the Maintenance and Lineage Commitment of Mouse Embryonic Stem Cells. FEBS Open Bio, 4, 112-120. http://dx.doi.org/10.1016/j.fob.2014.01.001

[76] Perez-Terzic, C., Faustino, R.S., Boorsma, B.J., Arrell, D.K., Niederlander, N.J., Behfar, A. and Terzic, A. (2007) Stem Cells Transform into a Cardiac Phenotype with Remodeling of the Nuclear Transport Machinery. Nature Reviews Cardiology, 4, S68-S76. http://dx.doi.org/10.1038/ncpcardio0763

[77] Lupu, F., Alves, A., Anderson, K., Doye, V. and Lacy, E. (2008) Nuclear Pore Composition Regulates Neural Stem/ Progenitor Cell Differentiation in the Mouse Embryo. Developmental Cell, 14, 831-842. http://dx.doi.org/10.1016/j.devcel.2008.03.011

[78] Jacinto, F.V., Benner, C. and Hetzer, M.W. (2015) The Nucleoporin Nup153 Regulates Embryonic Stem Cell Pluripotency through Gene Silencing. Genes \& Development, 29, 1224-1238. http://dx.doi.org/10.1101/gad.260919.115

[79] Yagita, K., Horie, K., Koinuma, S., Nakamura, W., Yamanaka, I., Urasaki, A., Shigeyoshi, Y., Kawakami, K., Shimada, S., Takeda, J. and Uchiyama, Y. (2010) Development of the Circadian Oscillator during Differentiation of Mouse Embryonic Stem Cells in Vitro. Proceedings of the National Academy of Sciences of the United States of America, 107, 3846-3851. http://dx.doi.org/10.1073/pnas.0913256107

[80] Malik, A., Jamasbi, R.J., Kondratov, R.V. and Geusz, M.E. (2015) Development of Circadian Oscillators in Neurosphere Cultures during Adult Neurogenesis. PLoS ONE, 10, e0122937. http://dx.doi.org/10.1371/journal.pone.0122937

[81] Malik, A., Kondratov, R.V., Jamasbi, R.J. and Geusz, M.E. (2015) Circadian Clock Genes Are Essential for Normal Adult Neurogenesis, Differentiation, and Fate Determination. PLoS ONE, 10, e0139655. http://dx.doi.org/10.1371/journal.pone.0139655

[82] Kageyama, R., Yoshiura, S., Masamizu, Y. and Niwa, Y. (2007) Ultradian Oscillators in Somite Segmentation and Other Biological Events. Cold Spring Harbor Symposia on Quantitative Biology, 72, 451-457. http://dx.doi.org/10.1101/sqb.2007.72.012 